\title{
Preservation of the Intercostobrachial Nerve during Axillary Dissection for Breast Cancer at the Surgical Oncology Unit of Cancer Department of Dakar University
}

\author{
Sidy Ka*, Michel Auguste Mouelle, Mohammed Ezzet Charfi, Jaafar Thiam, Souleymane Dieng, \\ Salif Balde, Moustapha Dieng, Ahmadou Dem
}

Centre Hospitalier, Universitaire Le Dantec, Dakar, Sénégal

Email: *kasidyoasis@gmail.com

How to cite this paper: Ka, S., Mouelle, M.A., Charfi, M.E., Thiam, J., Dieng, S., Balde, S., Dieng, M. and Dem, A. (2022) Preservation of the Intercostobrachial Nerve during Axillary Dissection for Breast Cancer at the Surgical Oncology Unit of Cancer Department of Dakar University. Advances in Breast Cancer Research, 11, 63-68.

https://doi.org/10.4236/abcr.2022.111004

Received: January 2, 2022

Accepted: January 26, 2022

Published: January 29, 2022

Copyright $\odot 2022$ by author(s) and Scientific Research Publishing Inc. This work is licensed under the Creative Commons Attribution International License (CC BY 4.0).

http://creativecommons.org/licenses/by/4.0/

\begin{abstract}
The intercostobrachial nerve (ICBN) is responsible for the sensory innervation of a part of the inner side of the arm. Injury of the intercostobrachial nerve is a complication of axillary dissection during lymph node dissection. Objective: This study aimed to determine the effect of preservation of the intercostobrachial nerve on postoperative sensory disturbances. Methods: This is a prospective, single-center study which was carried out in 90 patients followed in the oncology department of the Aristide Le Dantec hospital in Dakar, suffering from breast cancer and having undergone breast surgery associated with axillary dissection, for a period of 6 months. The patients were divided into two groups depending on whether the intercostobrachial nerve (ICBN) was preserved or not. The two groups were compared in terms of the incidence of sensory disturbances. Results: Sixty patients without nerve preservation and 30 patients with nerve preservation were included in the study, i.e., 90 patients in total. ICBN was injured in 60 patients of which 41 patients (83.7\%) developed numbness in the inner arm. While in the preserved group, only 8 patients suffered from numbness (16.3\%) with a significant $P$ value of 0.002 ; however, for other variables such as the incidence of neuropathic pain and hypoesthesia-like sensory deficit, there was no significant difference. Conclusion: Preservation of the intercostobrachial nerve during axillary dissection for breast cancer reduces the incidence of sensory disturbances on the upper limb.
\end{abstract}

\section{Keywords}

Axillary Dissection, Intercostobrachial Nerve, Pain, Hypoesthesia 


\section{Introduction}

Treatment of the armpit in breast cancer is by axillary dissection or sentinel node biopsy depending on whether there is lymph node involvement or not [1] [2]. In the event of a metastatic sentinel node, complementary axillary dissection remains the rule despite the frequency of complications, in particular lymphedema, pain and sensory disturbances due to the section of the intercostobrachial nerve [3] [4]. The need for the preservation of the ICBN during axillary dissection is controversial. In our practice, breast cancer cases are all advanced and all patients undergo axillary dissection during surgery. The objective of this study was to determine the effect of ICBN preservation on the incidence of postoperative sensory disturbances in our setting.

\section{Methods}

This was a prospective, single-center, non randomized cohort study carried out at the Cancer Department of Aristide Le Dantec Hospital in Dakar over 6 months, between February and July 2021. Patients eligible for the study had undergone breast surgery with axillary dissection. When a branch distributing to the arm was preserved, this was classified as nerve preservation (Figure 1). The patients were distributed in 2 groups depending on the possibility of preservation of the nerve. The choice was independent of the initial stage and the response to chemotherapy. The files retained concerned patients whose surgeon involved in the study mentioned the concept of dissection and conservation of the nerve, and the monitoring and evaluation of the incidence of dissection of the nerve on the upper limb.

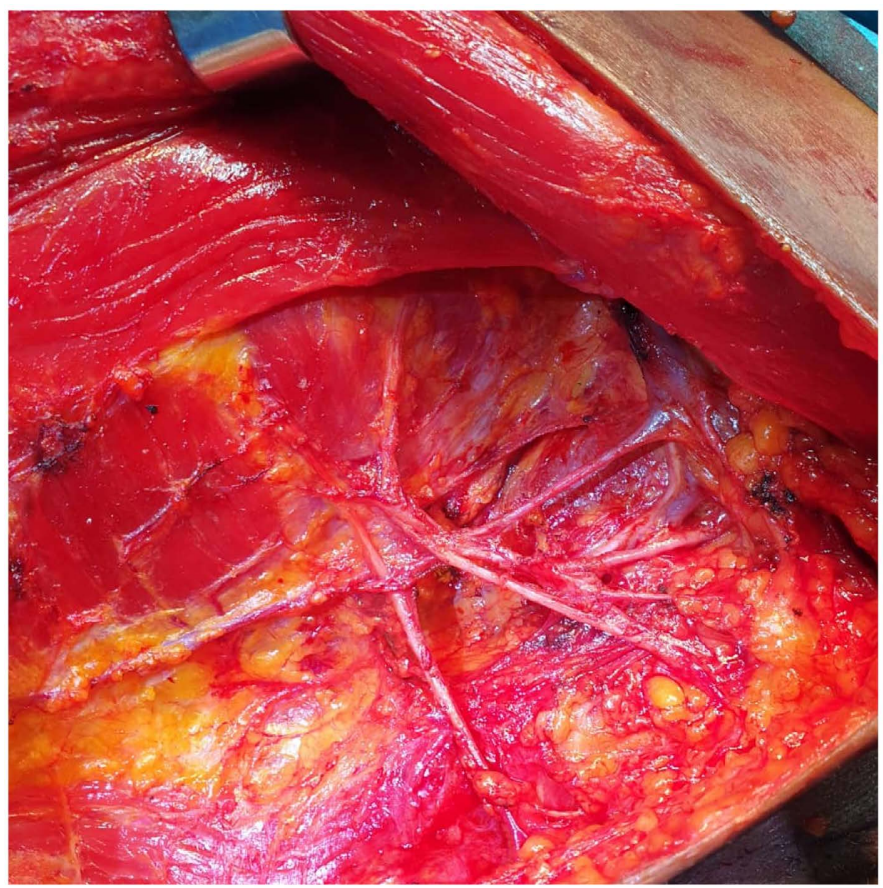

Figure 1. Mastectomy with axillary lymph node dissection and ICBN Preservation. 
The main results of this study were the assessment of neuropathic pain and sensory disturbances such as anesthesia, hypoaesthesia, paraesthesia and numbness in the upper limb. We assess the neuropathic pain and sensory disturbances clinically by neurologic examination. We did not use electromyographic nerve assessment. We compared 2 arms depending on whether the nerve was retained or not. The data was collected on a form report and then recorded in Microsoft Excel before being analyzed on EPI Info. The associations between the two groups of patients and the clinical effects on the nerve were measured by a logistic regression model and expressed by the Odd ratio with $95 \%$ confidence interval.

\section{Results}

During 6 months at the Joliot Curie Institute of Le Dantec hospital in Dakar, 90 patients were included, either 30 with preservation of the ICBN (33.3\% in group $\mathrm{P})$ and 60 patients with division of the ICBN (66.7\% in group D).

\subsection{Epidemiological and Clinical Characteristics of Patients}

The average age of the patients was 43.42 years \pm 11.88 , with extremes between 25 and 80 years. The most affected age group was that of 30 to 40 years. The most represented histological type was invasive carcinoma of non-specific type at $91.1 \%$ followed by lobular carcinoma. SBR II histoprognostic grade moderately differentiated tumors were the most represented at $71.1 \%$ followed by SBR III grade. The luminal A subtype was the most represented at $42.9 \%$ followed by triple negative tumors at $28.5 \%$. Stage IIIB was the most represented followed by stage IV with $37.8 \%$ and $25.6 \%$ respectively and 83 patients (92.2\%) received neoadjuvant chemotherapy, 58 patients in group $\mathrm{D}$ and 25 patients in group $\mathrm{P}$.

\subsection{Evaluation of Surgery Effect}

Postoperative pain was found in $\mathrm{P}$ and $\mathrm{D}$ groups. They were present in total in 49 patients, i.e., 41 patients in Group D vs 8 patients in group $\mathrm{P}$ (Table 1). There is a statistically significant difference in the 2 arms with a $(P=0.001)$, a relative

Table 1. Postoperative sensitivity assessment.

\begin{tabular}{cccccc}
\hline Variables & $\begin{array}{c}\text { D groupe } \\
(60)\end{array}$ & $\begin{array}{c}\text { P groupe } \\
(30)\end{array}$ & P value & $\begin{array}{c}\text { Interval of } \\
\text { confidence 95\% }\end{array}$ & RR \\
\hline Hypoaesthesia & 47 & 06 & 0.001 & $0.25[0.12-0.52]$ & 0.25 \\
Pain feeling & 41 & 08 & 0.001 & $0.39[0.21-0.72]$ & 0.39 \\
Mild pain (2/10) & 21 & 06 & 0.002 & & \\
Moderate pain (4/10) & 18 & 01 & & & \\
Electric shocks & 34 & 07 & 0.012 & & \\
Numbness & 30 & 03 & 0.002 & & \\
\end{tabular}


risk $(\mathrm{RR}=0.39), 95 \% \mathrm{CI}$ between [0.21 and 0.724]. Injury to the nerve therefore seems to have a clear negative effect on pain.

Pain was more intense according to the visual analogue scale (VAS) in group D compared to group P. 21 patients in group D presented mild pain (VAS 2/10) vs 6 patients in group $P$ followed by 18 patients in group D who presented moderate pain (VAS 4/10) vs 1 patient in group P. We note a significant difference between the 2 groups with a $\mathrm{P}=0.002$. Electric like paresthesia was the main characteristic of pain in our series, 34 patients in group D vs 7 patients in group $\mathrm{P}$. We found a statistically significant difference with one $(\mathrm{P}=0.012)$ in the 2 groups.

Numbness was found in 30 patients in group $\mathrm{D}$ vs. 3 patients in group $\mathrm{P}$ with a statistically significant difference. Concerning neuropathic pain, 10 patients in group $\mathrm{D}$ versus 1 patient in group $\mathrm{P}$ presented neuropathic pain (with a score $>$ $4 / 10)$. We noted a statistically significant difference in the 2 groups $(P=0.027)$. Although the incidence of a DN score $>4$ (neuropathic score) is zero in the group of preserved, we note an $\mathrm{RR}=1.2$ (95\% CI 1.07 to 1.34 ) for $\mathrm{DN}$ less than or equal to 4 or $20 \%$ chance, once preserved, of having a DN score less than or equal, therefore of causing less neuropathic complication compared to group D.

53 patients presented with dysesthesia, i.e., 58.9\%. 47 patients in Group D vs 6 patients in group $\mathrm{P}$ presented dysesthesia with $\mathrm{P}=0.001$. We noted a statistically significant difference in the 2 groups. For hypoaesthesia, 47 patients in group D vs 6 patients in group $\mathrm{P}$ presented with hypoaesthesia. We noted a statistically significant difference in the 2 groups $(P=0.001)$, an $R R=0.25 \%$ and $95 \% \mathrm{CI}$ between 0.12 and 0.52 . This means that patients in the Preserved group have a $75 \%$ chance of having less hypoaesthesia compared to those in the $\mathrm{D}$ group.

Sensitive deficit was more frequent with $88.4 \%$ versus $11.3 \%$. Statistical evaluation noted a significant correlation in the 2 groups with a significant $\mathrm{P}(\mathrm{P}=0.001)$, an $\mathrm{RR}=0.25$ and $95 \% \mathrm{CI}$ between 0.12 and 0.52 . This means that patients in the Preserved group have a $75 \%$ chance of having less hypoaesthesia compared to those in the D (divided) group. Finally, a gesture of preservation makes it possible to avoid a sensory deficit in more than half of the cases.

\section{Discussion}

Axillary dissection is the standard treatment for breast cancer with positive nodes [1] [5]. The Intercostobrachial nerve is commonly encountered during axillary dissection as it passes through axillary fat. The difficulties arise from anatomical variations, the size of the fatty tissue and possible axillary tumor invasion [4].

The intercostobrachial nerve is still frequently the object of surgical sacrifice, some authors considering its preservation either as unnecessary or as technically difficult (lengthening of the operating time) [6]. A few studies have attempted to prove the frequency of clinical consequences of such an injury.

Sensory deficit is common and in the order of $80 \%$ in European journals in cases of nerve damage. In the Taylor et al. series, the frequency of hypoaesthesia 
was $71.7 \%$ vs. $37.5 \%$ in the group where the nerve was preserved [7]. In Torresan et al., the frequency of hypoaesthesia in the group where the nerve was severed was $83.3 \%$ compared to that of the preserved group which was $46.3 \%$ [8].

Severing a nerve trunk causes neuropathic pain. Chronic neuropathic pain was frequent after axillary dissection for breast cancer, being associated with anxiety and arm symptoms before breast cancer treatments and type of surgical management [9]. Chronic pain that persists more than 2 months after breast cancer surgery is considered primarily neuropathic, commonly referred to as post mastectomy pain syndrome [10]. Preservation of the intercostobrachial nerve is possible. It does not alter the tumor prognosis and does not significantly lengthen the operating time [7] [8].

There are several arguments for favoring sentinel lymph node biopsy as a means of avoiding lymph node dissection, which is potentially more iatrogenic. Miguel [11] thus shows that the development of this approach has made it possible to reduce the number of patients presenting severe pain in the territory of the ICBN. This is a validated technique if there is no macroscopic axillary tumor invasion [7]. Finally, the preservation of the axillary cavity reduces the incidence of other postoperative complications, which occur with varying frequency.

Despite the conclusions of some authors for whom even after randomized studies, results do not demonstrate that ICBN preservation benefit to improve sensation. It seems that for all it improve quality of life and physical function of upper arm at 3 months after surgery [12].

The limitations of the study are related to the fact that the surgeons do not have the same experience of axillary dissection and of the follow-up which is short.

\section{Conclusion}

Preservation of the intercostobrachial nerve during axillary dissection for breast cancer reduces the incidence of sensory disturbances on the upper limb. Prevention of neuropathic pain is therefore essential. This remains possible and must be an integral part of the surgical strategy for breast cancer, taking into account the possibilities of sentinel node biopsy and preservation of the intercostobrachial nerve.

\section{Conflicts of Interest}

There are no conflicts of interest.

\section{References}

[1] Warrier, S., Hwang, S., Koy, C.E., et al. (2014) Preservation or Division of the Intercostobrachial Nerve in Axillary Dissection for Breast Cancer: Meta-Analysis of Randomised Controlled Trials. The Breast, 1-7. https://doi.org/10.1016/j.breast.2014.05.020

[2] Giuliano, A.E., Hunt, K.K., Ballman, K.V. et al. (2011) Axillary Dissection vs No Axillary Dissection in Women with Invasive Breast Cancer and Sentinel Node Metastasis: A Randomized Clinical Trial. Journal of the American Medical Association, 305, 569-575. https://doi.org/10.1001/jama.2011.90 
[3] Bilimoria, K.Y., Bentrem, D.J., Hansen, N.M. et al. (2009) Comparison of Sentinel Lymph Node Biopsy alone and Completion Axillary Lymph Node Dissection for Node Positive Breast Cancer. Journal of Clinical Oncology, 27, 2946-2953. https://doi.org/10.1200/JCO.2008.19.5750

[4] Galimberti, V., Cole, B.F., Zurrida, S., et al. (2013) Axillary Dissection versus No Axillary Dissection in Patients with Sentinel Node Micrometastases (IBCSG 23-01): A Phase 3 Randomized Controlled Trial. The Lancet Oncology, 14, 297-305. https://doi.org/10.1016/S1470-2045(13)70035-4

[5] Magnoni, F., Galimberti, V., Corso, G., Intra, M., Sacchini, V. and Veronesi, P. (2020) Axillary Surgery in Breast Cancer: An Updated Historical Perspective. Seminars in Oncology, 47, 341-352. https://doi.org/10.1053/j.seminoncol.2020.09.001

[6] Abdullah, T.I., Iddon, J., Barr, L., et al. (1998) Prospective Randomized Controlled Trial of Preservation of the Intercostobrachial Nerve during Axillary Node Clearance for Breast Cancer. British Journal of Surgery, 85, 1443-1145.

https://doi.org/10.1046/j.1365-2168.1998.00843.x

[7] Taylor, K.O. (2004) Morbidity Associated with Axillary Surgery for Breast Cancer. ANZ Journal of Surgery, 74, 314-317. https://doi.org/10.1111/j.1445-1433.2004.02992.x

[8] Torresan, R.Z., Cabello, C., Conde, D.M., et al. (2003) Impact of the Preservation of the Intercostobrachial Nerve in Axillary Lymphadenectomy due to Breast Cancer. The Breast Journal, 9, 389-392. https://doi.org/10.1046/j.1524-4741.2003.09505.x

[9] Pereira, S., Fontes, F., Sonin, T., Dias, T., Fragoso, M., Castro-Lopes, J. and Lunet, N. (2017) Neuropathic Pain after Breast Cancer Treatment: Characterization and Risk Factors. Journal of Pain and Symptom Management, 54, 877-888. https://doi.org/10.1016/j.jpainsymman.2017.04.011

[10] Macrae, W.A. and Davies, H.T.O. (1999) Chronic Postsurgical Pain. In: Crombie, I.K., Ed., Epidemiology of Pain. Seattle, 125-142.

[11] Miguel, R., Kunh, A.M., Shons, A.R., et al. (2001) The Effect of Sentinel Node Selective Axillary Lymphadenectomy on the Incidence of Postmastectomy Pain Syndrome. Cancer Control, 8, 427-430. https://doi.org/10.1177/107327480100800506

[12] Chirappapha, P., Arunnart, M., Lertsithichai, P., Supsamutchai, C., Sukarayothin, T. and Leesombatpaiboon, M. (2019) Evaluation the Effect of Preserving Intercostobrachial Nerve in Axillary Dissection for Breast Cancer Patient. Gland Surgery, 8, 599-608. https://doi.org/10.21037/gs.2019.10.06 